\title{
The Effectiveness of a Nurse-led Behavioral Activation Intervention in Hospitalized Depressed Elderly: a Pragmatic Cluster-randomized Clinical Trial.
}

Frans Clignet

VU Amsterdam

Annemieke van Straten

VU Amsterdam

Pim Cuijpers

VU Amsterdam

Berno van Meijel ( $\square$ Berno.vanmeijel@inholland.nl )

Inholland University of Applied Sciences

\section{Research Article}

Keywords: elderly, depression, Behavioral Activation, RCT, nursing

Posted Date: May 28th, 2021

DOI: https://doi.org/10.21203/rs.3.rs-533935/v1

License: @ (1) This work is licensed under a Creative Commons Attribution 4.0 International License. Read Full License 


\section{Abstract}

Background: Approximately $10 \%$ of the elderly suffer from Major Depressive Disorder (MDD). The purpose of this study is to examine the effectiveness of a nurse-led behavioral activation program (the Systematic Activation Method), in depressed elderly.

Methods: A cluster-randomized clinical trial in which ten hospital units were randomized as either an experimental unit or control unit (care-as-usual). Data was collected at baseline (T0), eight weeks later (post intervention=T1), and six months later (follow-up=T2). Primary outcome was severity of depressive symptoms. For the analysis multilevel linear models were used. We calculated the size of the effects with Hedges' $g$ (and their 95\% confidence intervals).

Results: 55 patients were included ( $n=30$ experimental, $n=25$ control). The results showed that there were moderate post-intervention effects of the Systematic Activation Program in the reduction of depressive symptoms ( $g=0.35)$, but these effects were not statistically significant.

Conclusions: The inclusion of patients was lower than calculated in the power analysis. A more intensive focus on applying motivational techniques and tailored implementation strategies might increase treatment effects on the patients.

Trial registration: Dutch Trial Register NTR 1809.

\section{Introduction}

Point prevalence estimates for affective disorders among the elderly (55 years and older) vary, but seem to be about $10 \%$ for Major Depressive disorder (MDD) (Sjöberg, Karlsson, Atti, Skoog, Fratiglioni \& Wang, 2017). The prognosis for MDD among the elderly is generally poor: more than $40 \%$ has an unfavorable but fluctuating course and in about a third of the cases there is a severe and chronic course (Jeurink et al., 2018). Some of those chronic and severe cases need hospitalization.

There are several effective psychological treatments available for MDD, which also seem to be effective among the elderly (Cuijpers et al., 2020). However, the studies in this meta-analysis have generally been conducted in younger and outpatient adults with few studies focusing on the oldest and most severe. A meta-analysis specifically aimed at the effects of psychological treatments for hospitalized depressed patients showed a small (hedges $g=0.29$ ) but statistically significant effect compared to usual care including pharmacological treatment (Cuijpers, Clignet, van Meijel, van Straten, Li \& Andersson, 2011).

Even though psychological treatments seem to be effective they are not commonly offered to inpatients, and psychotherapists in inpatient settings are scarce. The most common treatments in routine inpatient care are medication, occupational therapy, and psychosocial support delivered by nurses (National Institute for Health and Clinical Excellence, 2009). Behavioral Activation (BA) is a suitable treatment modality for nurses because its effectiveness and the emphatic focus on activation. It has been demonstrated that BA yields the same effect as Cognitive Behavioral Therapy (CBT), while BA requires less extensive training as CBT (Richards et al., 2016).

BA aims to make patients aware of the association between mood and the number of pleasant activities. In BA, the therapist serves as a coach to re-engage patients with pleasant activities while monitoring mood and thus creating positive reinforcements (Cuijpers, van Straten \& Warmerdam, 2007).

The aim of the present study was to investigate the effectiveness of BA delivered by nursing staff in inpatient elderly with MDD.

\section{Methods}

\section{Design}

To study the effects of the nurse-led BA intervention, a pragmatic multicenter cluster-randomized clinical trial was conducted according to the CONSORT criteria (Rennie, 2001). Hospital units were randomized to either experimental units where patients received SAM as an adjunctive intervention (next to care-as-usual), or control units where the patients only received care-as-usual. The study protocol was described in detail by Clignet, Van Meijel, Van Straten and Cuijpers (2012a).

\section{Psychiatric hospitals}


The study was conducted in ten inpatient mental health units in six psychiatric hospitals in the Netherlands. These units provide treatment for elderly ( $\geq 60$ years) patients with different types of mental disorders, with the exception of dementia. Two units were restricted (meaning that patients could only leave the building after permission of the staff) and eight were open (meaning that patients could leave if they want).

Matching was based on level of restraint (open or closed units), and an estimation of the average time spent on occupational therapy and other therapeutic activities. An independent researcher randomized the matched units with a random allocation generator.

\section{In- and exclusion criteria}

Inclusion criteria were: a) a primary diagnoses of Major Depressive disorder according to the Diagnostic and Statistical Manual for Mental Disorders fourth edition (DSM-IV; American Psychiatric Association, 2000). The MINI International Neuropsychiatric Interview (Van Vliet, Leroy \& Van Megen, (2000) was used to ascertain the diagnosis, b) age 60 years or older; c) able to read and write in Dutch; d) giving written informed consent. The only exclusion criterion was: cognitive impairments. This was measured with the Minimal Mental State Examination (MMSE) (Folstein, Folstein, \& McHugh, 1975). Patients with a MMSE score of 23 or lower were excluded.

Power was calculated, based on previous research (Hopko, Lejuez, Lepage, Hopko \& McNeil, 2003; Cuijpers et al., 2007), with an estimated effect size of $d=0.7(a=0.05$, power $1-\beta=0.8)$. Based on these calculations, 102 participants had to be included in total.

\section{Recruitment procedure}

The principal investigator visited every participating unit weekly to check for newly admitted patients with MDD as a primary or secondary diagnosis. Nurses working on the unit then informed the eligible patients. They handed out the information brochure, the informed consent form and the baseline questionnaire. Those patients who were willing to participate were then contacted for a telephone interview with the principal investigator. During this interview, the study was further explained, if necessary, and the MINI and the MMSE were administered. The signed informed consent forms and baseline questionnaires were gathered during the next site visit.

\section{The Intervention}

The Systematic Activation Method (SAM) is a simplified version of BA. It is a highly structured seven-week course with a weekly session with a nurse. The main ingredients of the course are keeping up a mood diary and the execution of activities that a potentially pleasant. In the first session, patients were educated on the treatment rationale and executed an exercise in keeping up a mood diary. During the second session, patients added some potentially pleasant activities to their daily routine using the "pleasant activity list" (Lewinsohn \& Amenson, 1978; MacPhillamy \& Lewinsohn, 1982). In the following two sessions (3 and 4) patients developed and executed a pleasant activity plan. During the fifth session the patient explored how to use external resources (friends or relatives) to support them during the execution of the positive activity plan. During the sixth session, the patient set up an Activity Experiment in which an activity was planned which was considered to be very difficult. During the last session the patients learned how to use the SAM in relapse prevention by discussing how to prevent the pitfalls that are caused by the depression.

These steps are described in a course book, which every patient receives at the start. It contains an overview of the treatment rationale, instructions and all the necessary schemas and diaries. The sessions were guided by trained nurses, which took place prior to the implementation of the SAM at the units. The nurses were trained by the principal investigator and consisted of two four-hour sessions in which attention was paid to the theoretical underpinning of the intervention program, the use of motivational techniques and the execution of the SAM. In order to maximize treatment integrity, supervision meetings once per two weeks at the unit were organized, and additional consultation was provided via telephone or e-mail. We measured adherence to the intervention by asking patients to fill out how many lessons and homework assignments they had performed. The intervention is described in more detail by Clignet, Van Meijel, Van Straten, Lampe \& Cuijpers. (2012). The SAM was added to Care-as-Usual (CAU) in the experimental groups.

\section{Care-as-usual}

All participants (experimental and control) received CAU. CAU in inpatients usually consists of occupational therapy, medication, and supportive therapy. We monitored the use of psychiatric medication for each patient. Other therapeutic activities were not measured at patient level but the average number of hours for a typical week per unit was assessed: total number of hours occupational therapy was provided (including activities such as hobby training, art classes etc.), total number of hours possible other forms of psychotherapy were provided (group or individual), and the average time of individual contacts with a psychiatrist and with a nurse.

\section{Data collection and measurements}

Page 3/11 
All data were collected through self-report paper and pencil questionnaires. We measured: at baseline (T0), eight weeks later (post intervention = T1), and six months later (follow-up = T2). At baseline, we registered socio-demographic characteristics (age, gender, nationality, marital status, educational level), information about former episodes of MDD, previous treatment for mental health problems, co-morbid physical or psychiatric diseases, cognitive status and current medication use. At each assessment we measured depressive symptoms (primary outcome), and symptoms of anxiety and level of mastery (secondary outcomes). Depressive symptoms were measured by the Dutch version of the Beck Depression Inventory, second edition (BDI-II-N; Beck, Steer \& Brown, 1996; Van der Does, 2002) that contains 21 items. All items are rated on a four-point Likert scale $(0=$ no problems to $3=$ severe problems $)$. The total score ranges from 0 (no depression) to 63 (severe depression). Anxiety was measured because of its high comorbidity with depression (Hirschfeld, 2001). It was measured by the Anxiety subscale of the Hospital Anxiety Depression Scale (HADS-A) (Zigmond \& Snaith, 1983). This subscale includes 7 items, which are rated on a four-point Likert scale $(0=$ no problems to $3=$ severe problems). The total score ranges from 0 (no anxiety symptoms) to 21 (severe anxiety symptoms). Increasing mastery is one of the main working mechanisms of SAM. The level of mastery was assessed with the five-item Pearlin Mastery Scale (Pearly \& Schooner, 1978). The items are rated on a five-point Likert scale $(1=$ no control to $5=$ maximum control). The total score ranges from 5 (low mastery) to 25 (high mastery).

\section{Statistical analyses}

To test if randomization had been successful, we examined the differences between the intervention and control group at baseline. We used independent $t$ - tests for continuous data and chi-square tests for categorical data.

To answer the primary research question (whether the SAM is considered an effective adjunctive intervention compared to care-asusual) we used two statistical procedures. First, we used multilevel linear models. These models take account the hierarchical structure of the data (unit and patient level) and calculate the changes in the dependent variables over time. The model included a between-factor (group: experimental vs. control) and a within-factor (time: T0, T1, and T2). We examined for each of the dependent variables (BDI, HADS-A, PMS) a group main effect, a time main effect, and a group *time interaction effect. A first order autoregressive level-one error structure was used in the final model, as it was the only structure that showed convergence.

Secondly, we calculated the size of the effects with Hedges' $g$ (and their $95 \%$ confidence intervals). We used intention-to-treat analyses and imputed missing data. First, we imputed the missing values on item level by using a corrected item mean. This means that the item score is estimated based on the overall mean performance of the person on the questionnaire as well as the mean performance on the items across persons (Kadengye, Ceulemans \& Van den Noortgate, 2012; Van Ginkel \& van Ark, 2005). Second, we imputed total scores for patients who did not fill out the questionnaire at all. We used the multiple imputation procedure (using Fully Conditional Specification) as provided in the SPSS software package and described by Van Buuren (2007). We created twenty datasets and Hedges'g was calculated on pooled means and standard deviations of these datasets. Effect sizes of $0.00-0.32$ can be considered as small, $0.33-0.55$ as medium, and $>0.56$ as large (Lipsey, 1990; Lipsey \& Wilson, 1993). For the calculation of Hedges' $g$ we used an effect size calculator (derived from http://www.cem.org/effect-size-calculator, 03-17-2015). All other analyses were performed in SPSS 20.

\section{Results}

\section{Participants' flow}

A total of 704 patients were admitted to the participating units during the inclusion period (May 2009-April 2011) and 294 of them were potentially eligible for inclusion because they were admitted with a MDD as a primary or secondary diagnosis. Of this group, 23 patients were excluded because they were too severely cognitively impaired or did not meet criteria for depression during our MINI interview. Another 152 patients declined participation, 45 were discharged before inclusion could take place, and 19 were not included for other reasons (e.g. admittance to a general hospital for surgery). Thus, a total of 55 participants were included in the study: 30 were allocated to an intervention unit and 25 to a control unit (see flowchart, Fig. 1).

Of the 55 patients, 10 (18\%) patients dropped out at T1 ( $n=3$ control group, $n=7$ experimental group). At T2 a further 12 patients dropped out (all experimental group). The total dropout at T2 was 21 (38\%). The baseline characteristics of the patients who dropped out at T2 did not differ significantly from the patients who completed the entire study. The reasons for dropout are described in Fig. 1.

Description of the sample

Page $4 / 11$ 
The baseline characteristics of the 55 participants are summarized in Table 1. The average age was 73 years (SD \pm 7.78$)$ and most of the participants were female $(n=34,61.8 \%)$. Furthermore, about half of the participants were living alone $(n=29,52,7 \%)$, most were of Dutch origin $(n=51,92.6 \%)$, about half had 10 years or less of formal education $(n=26,52 \%)$ and about a third $(36 \%)$ had four or more co-morbid physical diseases. Almost all participants $(n=44,80 \%)$ had a history of depression and almost $30 \%$ had been hospitalized three times or more in the past. The mean depression score (BDI) was $26.29(\mathrm{SD} \pm 9.53)$ and the mean anxiety score (HADS - A) was 10.98 (SD \pm 3.77 ). The mean Mastery score was 11.37 ( $S D \pm 3.88$ ). There were no statistically significant differences at baseline between the people in the intervention and control group.

Table 1

Patient characteristics. $a=$ Students $T$ test,$b=$ chi square test .

\begin{tabular}{|lllll|}
\hline Characteristic & Total & $\begin{array}{l}\text { Intervention } \\
(\mathbf{n = 3 0})\end{array}$ & $\begin{array}{l}\text { Control } \\
(\mathbf{n}=\mathbf{2 5})\end{array}$ & p.value \\
\hline Age, mean \pm SD & $73 \pm 7.78$ & $73,4 \pm 7.57$ & $72,5 \pm 8.17$ & $0.68 \mathrm{a}$ \\
\hline Female $\mathbf{n}(\%)$ & $34(61.8)$ & $18(60.0)$ & $16(64.0)$ & $0.76 \mathrm{~b}$ \\
\hline Social status, living alone $\mathbf{n}(\%)$ & $29(52.7)$ & $16(52.2)$ & $13(53.3)$ & $0.92 \mathrm{~b}$ \\
\hline Education $\leq \mathbf{1 0}$ years $\mathbf{n}(\%)$ & $26(52)$ & $18(60)$ & $11(44)$ & $0.24 \mathrm{~b}$ \\
\hline Non-Dutch origin $\mathbf{n}(\%)$ & $4(7.4)$ & $2(6,7)$ & $2(8)$ & $0.85 \mathrm{~b}$ \\
\hline Co morbid physical diseases $\mathbf{n} \geq \mathbf{4}$ (\%) & $20(36.4)$ & $13(43)$ & $7(28)$ & $0.24 \mathrm{~b}$ \\
\hline History of depression $\mathbf{n}=$ yes (\%) & $44(80)$ & $25(89.3)$ & $19(76)$ & $0.20 \mathrm{~b}$ \\
\hline History of admission $\mathbf{n} \geq \mathbf{3}$ times (\%) & $16(29.1)$ & $8(28,6)$ & $8(32)$ & $0.79 \mathrm{~b}$ \\
\hline Beck Depression Inventory, mean \pm SD & $26.29 \pm 9.53$ & $28.20 \pm 9.84$ & $24.29 \pm 8.85$ & $0.14 \mathrm{a}$ \\
\hline Anxiety Scale of the Hospital Anxiety and Depression Scale, mean \pm SD & $10.98 \pm 3.77$ & $11.70 \pm 3.34$ & $10.12 \pm 4.13$ & $0.12 \mathrm{a}$ \\
\hline Pearlin Mastery Scale, mean \pm SD & $11.37 \pm 3.88$ & $10.93 \pm 3.40$ & $11.88 \pm 4.39$ & $0.26 \mathrm{a}$ \\
\hline MMSE, mean \pm SD & $27,88 \pm 2.08$ & $27,62 \pm 2.07$ & $28,22 \pm 2.09$ & $0.31 \mathrm{a}$ \\
\hline
\end{tabular}

\section{Care as Usual}

The average length of clinical admission in both groups was approximately 100 days (experimental group 95 days; $S D=58$ ), control group 104 days $(S D=73 ; p=0.65)$. Eight weeks after baseline, at $T 1$, about half of the patients were still hospitalized $(57 \%$ control group; $48 \%$ experimental group), about a quarter were discharged but still receiving outpatient care (33\% control group; $22 \%$ experimental group) while the remaining patients were discharged without any further care ( $5 \%$ control group \& $30 \%$ experimental group).

There were no significant differences between the two groups in the percentage of patients using anti-depressant medication or benzodiazepines at post intervention as well follow - up. The use of antipsychotics however, differed significantly: $45 \%$ of patients in the control group used antipsychotics compared to $15.8 \%$ in the experimental group at post intervention $(T 1 ; p=0.05)$.

There were no significant differences between the two groups in in the amount of time spent in a typical week on occupational therapy psychotherapy group psychotherapy individual weekly contact with a psychiatrist and weekly contact with a nurse.

\section{Treatment adherence and evaluation}

Of the 30 patients randomized to the intervention $17(57 \%)$ returned the evaluation form about the intervention. On average the SAM was executed for a period of five weeks with an average of four meetings with a nurse. About a quarter of the patients $(24 \%)$ participated in the SAM for three weeks or less, almost half of the patients (47\%) participated for four or five weeks, while the remaining patients (29\%) participated for six weeks or more. With respect to the number of meetings, $29.4 \%$ of the participants had $0-2$ two meetings, $29.4 \%$ had four or five meetings and $17 \%$ had six meetings. One patient had ten meetings. 
At post-test there were no significant differences in pooled mean scores between the experimental and control group on depression, anxiety or mastery (Table 2). The post-test between-group effect sizes were (very) small. We also calculated between group effect sizes for the change scores (TO-T1). The experimental group improved more $(\mathrm{g}=0.3595 \% \mathrm{Cl}=-0.19-0.88)$ on depression than the control group. The same was true for anxiety $(\mathrm{g}=0.18(95 \% \mathrm{Cl}=-0.35-0.72)$ and mastery $(\mathrm{g}=0.31 ; 95 \% \mathrm{Cl}=-0.24-0.84)$. However, as can be seen from the $95 \%$ confidence intervals, none of the effect sizes were statistically significant.

The linear mixed model showed that both groups improved significantly between baseline and post-test on depression $(B D I ; F(1,131)=$ $10.89, p=0.01)$, anxiety (HADS; $F(1,128)=5.49, p=0.02)$ and mastery $(P M S ; F(1,85)=9.74, p=0.02 ;$ Table 3$)$. The model also showed that there were no significant differences in improvement between the experimental and control group. This was true for depression $(\operatorname{BDI} ; F(1,131)=1.141 p=0.29)$, anxiety $(\operatorname{HADS} ; F(1,128)=0.890 p=0.35)$ as well as for mastery $(P M S ; F(1,85)=1.03 p=0.31)$.

Table 2

Effect sizes (Hedges' g)

\begin{tabular}{|c|c|c|c|c|c|c|c|}
\hline \multicolumn{2}{|c|}{$\begin{array}{l}\text { Instrument/ } \\
\text { time }\end{array}$} & \multirow{3}{*}{$\begin{array}{l}\text { Experimental group }(n= \\
30) \\
\text { mean } \pm \text { SD } \\
28.20(9.84)\end{array}$} & \multirow{3}{*}{$\begin{array}{l}\text { Control group }(n= \\
25) \\
\text { mean } \pm \text { SD } \\
24.29(8.78)\end{array}$} & \multirow{3}{*}{$\begin{array}{l}\text { Hedges' } \\
\mathbf{g} \\
0.41\end{array}$} & \multicolumn{2}{|c|}{$\begin{array}{l}95 \% \text { Confidence interval for effect } \\
\text { size }\end{array}$} & \multirow{3}{*}{$\begin{array}{l}P \\
\text { value } \\
0.10\end{array}$} \\
\hline & & & & & \multirow{2}{*}{$\begin{array}{l}\text { Lower } \\
-0.13\end{array}$} & \multirow{2}{*}{$\begin{array}{l}\text { upper } \\
0.95\end{array}$} & \\
\hline BDI & TO & & & & & & \\
\hline & $\mathrm{T} 1$ & 18.85 (17.64) & $19.80(13.67)$ & -0.06 & -0.59 & 0.47 & 0.82 \\
\hline & $\begin{array}{l}\text { T0- } \\
\text { T1 }\end{array}$ & $9.35(15.77)$ & $4.20(13.49)$ & 0.35 & -0.19 & 0.88 & 0.18 \\
\hline & $\mathrm{T} 2$ & $21.99(5.48)$ & 18.45 (11.93) & 0.39 & -0.15 & 0.92 & 0.45 \\
\hline & $\begin{array}{l}\text { T1- } \\
\text { T2 }\end{array}$ & $-2.84(16.22)$ & $1.21(9.01)$ & -0.45 & -0.83 & 0.24 & 0.30 \\
\hline \multirow{5}{*}{$\begin{array}{l}\text { HADS- } \\
\text { A }\end{array}$} & TO & $11.7(3.34)$ & $10.12(4.13)$ & 0.42 & -0.12 & 0.96 & 0.12 \\
\hline & $\mathrm{T} 1$ & $9.21(6.32)$ & $8.62(5.88)$ & 0.09 & -0.44 & 0.63 & 0.71 \\
\hline & $\begin{array}{l}\text { T0- } \\
\text { T1 }\end{array}$ & 2.49 (5.77) & $1.50(4.66)$ & 0.18 & -0.35 & 0.72 & 0.68 \\
\hline & T2 & $10(11.56)$ & $9.75(5.23)$ & 0.03 & -0.50 & 0.56 & 0.92 \\
\hline & $\begin{array}{l}\text { T1- } \\
\text { T2 }\end{array}$ & $-0.86(10.37)$ & $-1.03(3.53)$ & 0.02 & -0.51 & 0.55 & 0.94 \\
\hline \multirow[t]{5}{*}{ PMS } & TO & $10.86(3.17)$ & $11.69(4.57)$ & 0.21 & -0.74 & 0.32 & 0.30 \\
\hline & $\mathrm{T} 1$ & $13.87(6.68)$ & $12.57(5.52)$ & -0.21 & -0.32 & 0.74 & 0.41 \\
\hline & $\begin{array}{l}\text { T0- } \\
\text { T1 }\end{array}$ & $2.95(7.55)$ & $0.56(8.10)$ & -0.31 & -0.23 & 0.84 & 0.26 \\
\hline & T2 & $11.47(12.18)$ & $14.07(8.74)$ & 0.24 & -0.77 & 0.29 & 0.40 \\
\hline & $\begin{array}{l}\text { T1- } \\
\text { T2 }\end{array}$ & $2.57(8.73)$ & $-1.43(5.91)$ & -0.52 & -1.06 & 0.02 & 0.13 \\
\hline
\end{tabular}

\section{Effects at follow-up}

Six months after baseline there were no statistically significant differences in depression, anxiety or mastery scores between the experimental and control group. The corresponding between group post-test effect sizes were $\mathrm{g}=0.39(95 \% \mathrm{Cl}=-0.15-0.92, \mathrm{p}=0.18)$ and $\mathrm{g}=0.24(95 \% \mathrm{Cl}=-0.77-0,29, \mathrm{p}=0.40)$. For anxiety, the effect size was close to zero $(\mathrm{g}=-0.03,95 \% \mathrm{Cl}=-0.50-0.52, \mathrm{p}=0.92)$. Again, we also compared change scores (between post-test and follow-up) thus taking into account any post-test differences. The effect sizes for depression and anxiety remained almost the same. The effect size for mastery increased $(\mathrm{g}=0.52,95 \% \mathrm{Cl}=-1.06-0.02, \mathrm{P}=0.13)$ in favor of the control group. The results were not statistically significant. 
The linear mixed model showed that there were no statistically significant improvements between post-test ( 8 weeks after baseline) and follow-up ( 6 months after baseline). The depression, anxiety and mastery scores remained unchanged. In addition, the linear mixed model showed that there were no significant differences in improvement (or deterioration) between the experiment and control group between T1 (8 weeks) and T2 (6 months) on the BDI, HADS - A and PMS.

Table 3

Linear Mixed Models. ${ }^{*}=p<0,05$.

\begin{tabular}{|c|c|c|c|c|c|c|c|c|c|c|c|c|c|c|c|}
\hline & \multicolumn{3}{|l|}{ Group } & \multicolumn{3}{|c|}{ TOvsT1 } & \multicolumn{3}{|c|}{ T1vsT2 } & \multicolumn{3}{|c|}{ Group*TOvsT1 } & \multicolumn{3}{|c|}{ Group*T1vsT2 } \\
\hline & B & bSE & $\begin{array}{l}95 \% \\
\mathrm{Cl}\end{array}$ & B & bSE & $\begin{array}{l}95 \% \\
\mathrm{Cl}\end{array}$ & B & bSE & $\begin{array}{l}95 \% \\
\mathrm{Cl}\end{array}$ & B & bSE & $\begin{array}{l}95 \% \\
\mathrm{Cl}\end{array}$ & B & bSE & $\begin{array}{l}95 \% \\
\mathrm{Cl}\end{array}$ \\
\hline BDI & $-1,29$ & 2.13 & $\begin{array}{l}-5.51- \\
2.93\end{array}$ & 5.96 & 1.96 & $\begin{array}{l}2.08- \\
9.84^{\star}\end{array}$ & 2.24 & 1.96 & $\begin{array}{l}-2.66- \\
7.14\end{array}$ & -2.91 & 2.73 & $\begin{array}{l}-8.31- \\
2.48\end{array}$ & -0.2 & 3.11 & $\begin{array}{l}-6.35- \\
5.96\end{array}$ \\
\hline HADS & -0.36 & 0.85 & $\begin{array}{l}-2.03- \\
1.32\end{array}$ & 1.78 & 0.75 & $\begin{array}{l}0.28- \\
3.28^{\star}\end{array}$ & 1.00 & 0.95 & $\begin{array}{l}-0.88- \\
2.88\end{array}$ & -1.02 & 1.08 & $\begin{array}{l}-8.31- \\
2.48\end{array}$ & -0.72 & 1.23 & $\begin{array}{l}-2.18- \\
1.73\end{array}$ \\
\hline PMS & -0.41 & 1.11 & $\begin{array}{l}-2.64- \\
1.83\end{array}$ & -1.68 & 0.60 & $\begin{array}{l}-2.86- \\
0.49 *\end{array}$ & -0.41 & 0.74 & $\begin{array}{l}-1.89- \\
1 .-7\end{array}$ & 0.82 & 0.81 & $\begin{array}{l}-0.79- \\
2.43\end{array}$ & -0.33 & 0.93 & $\begin{array}{l}-2.18- \\
1.53\end{array}$ \\
\hline
\end{tabular}

\section{Discussion}

The results showed that (1) depressive symptoms decreased significantly during the intervention period for both the intervention and control patients; (2) there were moderate post-intervention effects of SAM in the reduction of depressive symptoms $(g=0.35)$, level of anxiety $(g=0.18)$ and level of mastery $(g=0.31)$, but these effects were not statistically significant. However, since the dropout rates of the intervention group were high (response $37 \%$ ) these results are tentative.

One of the main reasons for the non-significant post-test results may be the lack of statistical power. Power was calculated, based on previous research (Hopko, Lejuez, Lepage, Hopko \& McNeil, 2003; Cuijpers et al., 2007), with an estimated effect size of $d=0.7$ ( $a=0.05$, power $1-\beta=0.8$ ). We aimed to include 102 participants (Clignet et al., 2012a) but only managed to include 55 . More than $50 \%$ of the eligible patients declined participation. A lack of motivation due to the nature of MDD and difficulties in motivating the patients by the nurses are the most likely explanations for the low inclusion of the participants.

There are two reasons, which could explain the low to moderate effect sizes we found. Firstly, because treatment integrity was lower than expected. Therefore, it is likely that the contrast between the control and intervention condition was too small to show a larger effect. Low treatment integrity was also found in other studies as an important factor for non-significant results (Dozeman et al. 2011; Snarski et al. 2011). For example, in the study of Dozeman et al. (2011) only $21 \%$ of the patients completed BA.

Secondly, both groups received considerable care already (occupational therapy etc), which might explain why patients in the control group also recovered significantly (Cuipers et al. 2011). Moreover, patients in the control group received significantly more anti-psychotic medication. This is an indication of possible differences in treatment regimes between the experimental or control groups as antipsychotic co - treatment is superior to mono treatment with antidepressants in the acute treatment of psychotic depression (Farahani \& Correll, 2012). We must stress though that the change score effect size of depression $(g=0.35)$ is comparable to the one found in the meta-analysis of psychological interventions for inpatients in our meta-analysis (Cuijpers et al. 2011), except that the effect size we found in this study was not significant.

\section{Strengths and limitations}

Our study has the following strengths. First, it can be considered a large study within the field of elderly inpatients. To our knowledge, studies on psychological therapies for inpatients only included up to 53 patients (Brand \& Clingempeel, 1992). Second, this is one of few studies on Behavioral Activation (BA) in this elderly population. And third, BA has been adapted so that nurses are able to execute the intervention. There are also a number of limitations that should be mentioned. There are also a number of limitations that should be mentioned. Some limitations can be attributed to randomization at unit level. Firstly, this means that there might have been differences between the care-as-usual of the experimental and control units. We stratified randomization on "usual therapy program" but we cannot rule out that there were still differences. Secondly, there might have been differences in the patient groups. Although the baseline characteristics were not significantly different, there might have been differences in characteristics we did not measure. Furthermore, it

Page $7 / 11$ 
was not possible to perform a subgroup analysis because of the relatively small sample size. This means that we were not able to calculate for which patients SAM was most effective.

\section{Conclusion}

Our results show that BA in this study (i.e. the SAM) seems to have small to moderate effects in addition to care as usual in inpatients with MDD. However, these results were not statistically significant. This might be due to the small sample size but also to other design factors (such as unit level randomization) or implementation factors (such as non-adherence to intervention). Therefore, it is too early to disregard the SAM as an effective intervention. First, the moderate effects we found for the reduction of depressive symptoms and increased mastery at post-intervention are indicators that patients could benefit from SAM, certainly when the differences in patient characteristics and the low treatment integrity are taken into account. Second, in future research, it is important to focus more intensively on the nurses' motivational skills in order to increase the uptake of BA and to ensure treatment integrity. However, this can only be done when adequate organizational conditions have been created e.g. when nurses are given enough time to carry out the SAM in addition to all their other demanding tasks.

To our knowledge, this is the first study in which BA is examined as a nursing intervention in elderly inpatients with MDD. The results of this study indicate that BA is not more effective than CAU in this population. A more intensive focus on applying motivational techniques might enhance the effects of BA when offered to an inpatient elderly population with MDD. This requires adequate application of motivational skills of mental health nurses. Training of motivational skills during basic and advanced nursing education is necessary. Furthermore, attention is necessary for tailored implementation strategies, taking into account the factors that affect the implementation of BA in an inpatient setting (Clignet, van Straten, Cuijpers \& van Meijel, 2016). This might increase treatment adherence of both professionals and patients.

\section{Abbreviations}

MDD: Major Depressive Disorder

BA: Behavioral Activation

CBT: Cognitive Behavioral Therapy

SAM: Systematic Activation Therapy

MINI: Mini International Neuropsychiatric Interview

MMSE: Minimal Mental State Examination

CAU: Care as Usual

BDI: Beck Depression Inventory

HADS: Hospital Anxiety Depression Scale

PMS: Pearlin Mastery Scale

\section{Declarations}

We declare that all methods were carried out in accordance with the Declaration of Helsinki and relevant guidelines and regulations.

Informed consent was obtained from all participants in this study.

\section{Ethical Approval}

The study was approved by the Medical Ethics Committee of the VU Medical Center (NL26878.029.09).

\section{Consent for Publication}


n.a.

\section{Availability of Data}

The datasets used and/or analysed during the current study are available from the corresponding author on reasonable request.

\section{Competing interests}

The authors declare that they have no competing interests.

\section{Conflict of interest}

The authors declare that there are no conflicts of interest.

\section{Funding}

This study is executed as a collaborative project between VU university, Altrecht institution for mental healthcare and Inholland University of Applied Sciences, and is partly funded by NutsOhra fund (funding no: 0902-75) and Continuendo Musearte (funding no: 09030200). The funders played no role in the study design, the collection, analysis and interpretation of data, or in the decision to submit the manuscript for publication.

\section{Authors' contributions}

FC was the principal researcher in this study, designed the study protocol, was responsible for data collection, performed the statistical analysis of the data, and wrote the drafts of the manuscript. PC was responsible for the entire research project, was involved in the design of the study, and revised the manuscript. AvS was involved in the design of the study and in data analysis, and revised the manuscript. BvM was also involved in project design, project supervision and revised. All authors approved the final version of the manuscript.

\section{Acknowledgements}

We would like to thank all the patients, nurses and administrators of Altrecht (location Zeist), Breburg (locations Etten-Leur and Tilburg), Dimence (Locations Deventer), GGZ Centraal (location Amersfoort), GGZ Drente (Location Assen) and Pro-Persona (Locations Arnhem, Ede and Nijmegen) for their contribution to this study. We also like to thank dr. Niels Smits, statistician at VU University for his contribution to the statistical analysis of this study.

\section{References}

1. American Psychiatric Association. (2000). Diagnostic and statistical manual of mental disorders (4th ed., text rev.). doi: 10.1176/appi.books.9780890423349.

2. Beck, A.T., Steer, R.A. \& Brown, G.K. (1996). Manual for the Beck Depression Inventory-II. San Antonio, TX: Psychological Corporation.

3. Van Buuren, S. (2007). Multiple imputation of discrete and continuous data by fully conditional specification. Statistical Methods in Medical Research, 16: 219-242. doi: 10.1177/0962280206074463.

4. Clignet, F., van Meijel, B., van Straten, A. \& Cuijpers, P. (2012a). The systematic activation method as a nursing intervention in depressed elderly: a protocol for a multi-centre cluster randomized trial. BMC Psychiatry, Sep 18; 12:144. doi: 10.1186/1471-244X12-144.

5. Clignet, F., van Meijel, B., van Straten, A. and Cuijpers, P. (2016). A Qualitative Evaluation of an Inpatient Nursing Intervention for Depressed Elderly: The Systematic Activation Method. Perspect Psychiatr Care, 14, 1-9. doi: 10.1111/ppc.12177.

6. Clignet, F., van Meijel, B., van Straten,A., Lampe, I. \& Cuijpers P. (2012). The Systematic Activation Method (SAM) in Depressed Elderly: A Case Report. Perspectives in Psychiatric Care, 48: 25-33. doi: 10.1111/j.1744-6163.2010.00297.x

7. Cuijpers, P., Karyotaki, E., Eckshtain, D., Ng, M.Y., Corteselli, K.A., Noma, H., Quero, S. \& Weisz, J.R. (2020). Psychotherapy for Depression Across Different Age Groups: A Systematic Review and Meta-analysis. JAMA Psychiatry, 77 (7), 694-702. doi: 10.1001/jamapsychiatry.2020.0164. 
8. Cuijpers, P., Clignet, F., van Meijel, B., van Straten, A., Li, J. \& Andersson, G. (2011). Psychological treatment of depression in inpatients: A systematic review and meta-analysis. Clinical Psychology Review, 31(3), 353-360. doi: 10.1016/j.cpr.2011.01.002.

9. Cuijpers, P., van Straten, A. \& Warmerdam, L. (2007). Behavioral activation treatments of depression: a meta-analysis. Clinical Psychology Review, 27(3), 318-326. doi: 10.1016/j.cpr.2006.11.001.

10. Van der Does, A.J.W. (2002). Handleiding bij de Nederlandse versie van Beck Depression Inventory, $2^{\text {nd }}$ edition (BDI-II-NL). Amsterdam: Pearson. [Manual for the Dutch version of the Beck Inventory].

11. Dozeman, E., van Schaik, D.J.F., van Marwijk, H.W.J., Stek, M.L., Beekman, A.T.F. \& van der Horst, H.E. (2011). Feasibility and effectiveness of activity-scheduling as a guided self-help intervention for the prevention of depression and anxiety in residents in homes for the elderly: a pragmatic randomized controlled trial. International Psychogeriatrics, 23(6), 969-978. doi: $10.1017 /$ S1041610211000202.

12. Farahani, A. \& Correll, C.U. (2012). Are antipsychotics or antidepressants needed for psychotic depression? A systematic review and meta-analysis of trials comparing antidepressant or antipsychotic monotherapy with combination treatment. The Journal of Clinical Psychiatry, 73(4),486-496. doi: 10.4088/JCP.11r07324

13. Faul, F., Erdfelder, E., Lang, A.G. \& Buchner, A. (2007). G*Power 3: a flexible statistical power analysis for the social, behavioral, and biomedical sciences. Behavior Research Methods, 39(2), 175-191. doi: 10.3758/BF03193146

14. Folstein, M.F., Folstein, S.E. \& McHugh, P.R. (1975). Mini-mental state: a practical method for grading the cognitive state of patients for the clinician. Journal of Psychiatric Research, 12(3), 189-98. doi: 10.1016/0022-3956(75)90026-6.

15. Van Ginkel, J. R., \& Van der Ark, L. A. (2005). SPSS syntax for missing value imputation in test and questionnaire data. Applied Psychological Measurement, 29: 152-153. doi: 10.1177/0146621603260688.

16. Hirschfeld, R.M.A. (2001). The comorbidity of major depression and anxiety disorders: Recognition and management in primary care. Primary Care Companion. J Clinical Psychiatry, 3(6), 244 - 254. doi: 10.4088/PCC.v03n0609.

17. Hopko, D.R., Lejuez, C.W., Lepage, J.P., Hopko, S.D. \& McNeil, D.W. (2003). A brief behavioral activation treatment for depression; A randomized pilot trial within an inpatient psychiatric hospital. Behavior Modification, 458-469. doi: 10.1177/0145445503255489.

18. Jeuring, H.W., Stek, M.L., Huisman, M., Oude Voshaar, R.C., Naarding, P., Collard, R.M., van der Mast, R.C., Kok, R.M., Beekman, A.T.F. \& Comijs, H.C. (2018). A Six-Year Prospective Study of the Prognosis and Predictors in Patients With Late-Life Depression. Am J Geriatr Psychiatry, 26 (9), 985-997. doi: 10.1016/j.jagp.2018.05.005.

19. Kadengye, D.T., Cools, W., \& Ceulemans, E. \& Van den Noortgate, W. (2012). Simple imputation methods versus direct likelihood analysis for missing item scores in multilevel educational data. Behav Res, 44, 516-531. doi: 10.3758/s13428-011-0157-x.

20. Lewinsohn, P.M., \& Amenson, C.S. (1978). Some relations between pleasant and unpleasant mood-related events and depression. Journal of Abnormal Psychology, 87(6), 644-654. doi: apa.org/journals/abn/87/6/644.pdf

21. Lipsey, M. W. (1990). Design Sensitivity: Statistical Power for Experimental Research. Thousand Oaks, CA: Sage Publications.

22. Lipsey, M. W. \& Wilson, D. B. (1993). The efficacy of psychological, educational, and behavioral treatment: confirmation from metaanalysis. American Psychology, 48, 1181-1209. doi: 10.1037/0003-066X.48.12.1181.

23. MacPhillamy, D.J. \& Lewinsohn, P.M. (1982). The pleasant events schedule: studies on reliability, validity, and scale Inter-correlation. Journal of Consulting and Clinical Psychology, 50(3), 363-380. doi: 10.1177/2167702613512793.

24. National Institute for Health and Clinical Excellence (NICE) (2009). Depression in Adults, the treatment and management of depression in adults, NICE clinical guideline 90, National Institute for Health and Clinical Excellence Level 1A, City Tower, Piccadilly Plaza, Manchester M1 4BT. Retrieved from: https://www.nice.org.uk/guidance/cg90.

25. Pearlin, L.I. \& Schooler, C. (1978). The structure of coping. Journal of Health and Social Behavior, 19(1), 1-21. doi: $10.2307 / 2136319$.

26. Rennie, D. (2001). CONSORT revised-improving the reporting of randomized trials. JAMA, 285, 2006-2007. doi: 10.1001/jama.285.15.2006.

27. Richards, D.A., Ekers, D.,McMillan, D., Taylor, R.S., Byford, S., Warren, F.C., . . Finning, K. (2016). Cost and outcome of behavioural activation versus cognitive behavioural therapy for depression (COBRA): a randomised, controlled, non-inferiority trial. Lancet, 388, 871-880. doi: 10.1016/S0140-6736(16)31140-0.

28. Sjöberg, L., Karlsson, B., Atti, A.R., Skoog, I., Fratiglioni, L., Wang, H.X. (2017). Prevalence of depression: Comparisons of different depression definitions in population-based samples of older adults. J Affect Disord., 221,123-131. doi: 10.1016/j.jad.2017.06.011. 
29. Van Vliet, I.M., Leroy, H., \& Van Megen, H.J.G.M. (2000). M.I.N.I. Plus: M.I.N.I. Internationaal Neuropsychiatrisch Interview: Nederlandse versie 5.0.0. Utrecht: Universitair Medisch Centrum Utrecht. [Manual M.I.N.I. International Neuropsychiatric Interview, Dutch version].

30. Zigmond, A.S. \& Snaith, R.P. (1983). The Hospital Anxiety and Depression Scale. Acta Psychiatrica Scandinavica, 67, $361-370$. doi: 10.1111/j.1600-0447.1983.tb0971

\section{Figures}

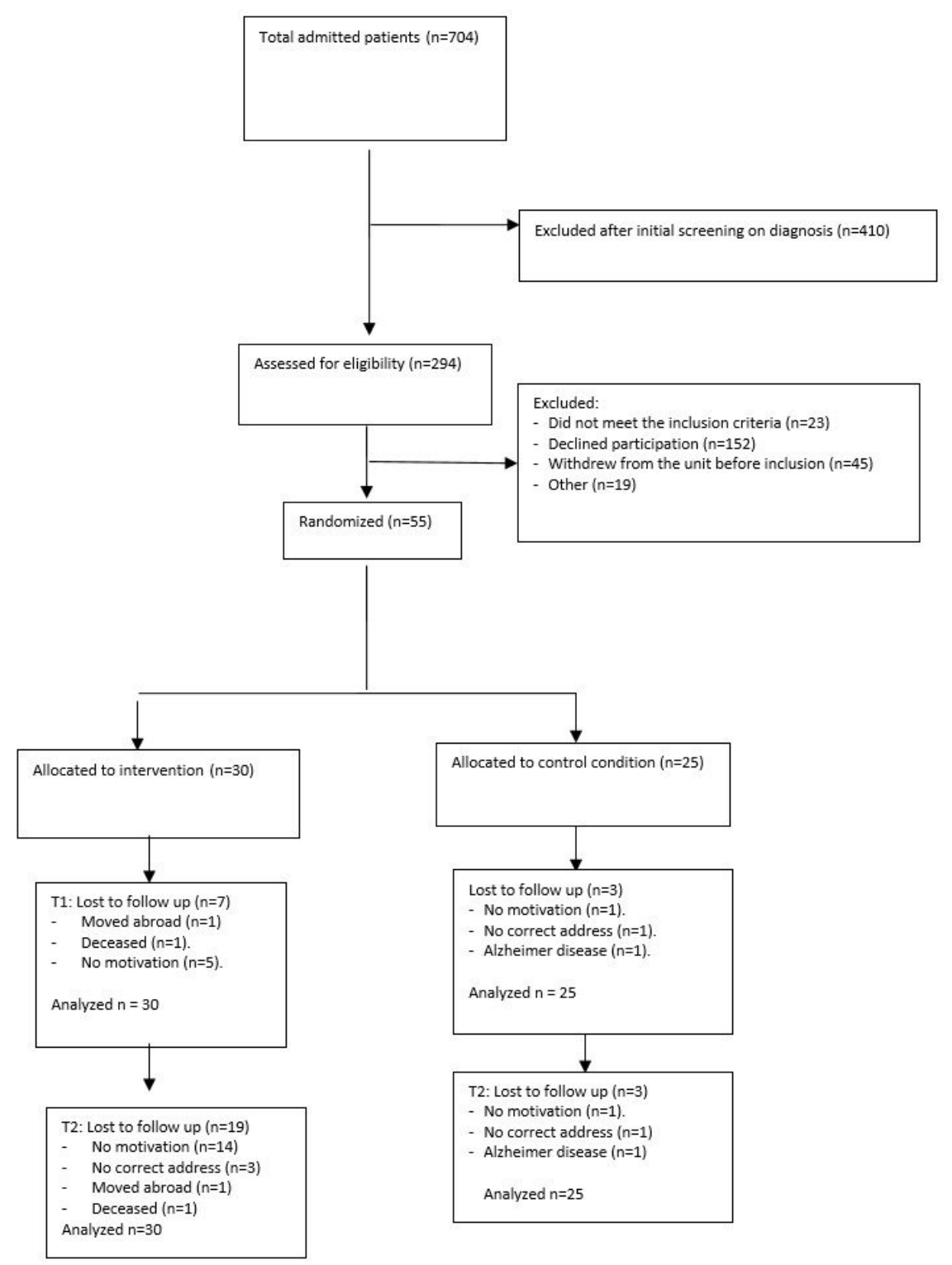

\section{Figure 1}

flowchart 